\title{
DESIGUALDADES SOCIOESPACIAIS
}

NAS CIDADES DO AGRONEGÓCIO ${ }^{1}$

\author{
DENISE ELIAS \\ RENATO PEQUENO
}

R E S U M O No Brasil, a territorialização do capital e a oligopolização do espaço agrário têm promovido profundos impactos socioespaciais, tanto no campo como nas cidades. Isto explica em parte a reestruturação do território e a organização de um novo sistema urbano, muito mais complexo - resultado da difusão da agricultura cientifica e do agronegócio globalizados - e que têm poder de impor especializaçôes produtivas ao território. Neste artigo, defende-se a tese de que é possivel identificar no Brasil agrícola moderno vários municípios cuja urbanização se deve diretamente à consecução e expansão do agronegócio, formando-se cidades cuja função principal claramente se associa às demandas produtivas dos setores associados à modernização da agricultura - sendo que nestas cidades se realiza a materialização das condiçôes gerais de reprodução do capital do agronegócio. Para tanto, são apresentados alguns pressupostos que explicariam este tipo de cidade, que denominamos de cidade do agronegócio. Da mesma forma, considerando que a difusão do agronegócio se dá de forma social e espacialmente excludentes, promovendo o acirramento das desigualdades, buscamos mostrar algumas das formas como elas se reproduzem nas cidades do agronegócio. A moradia é a principal variável de análise destas desigualdades.

P A L A V R A S - C H A V E Agricultura cientifica; agronegócio; reestruturação urbana; cidade do agronegócio; desigualdades socioespaciais.

\section{INTRODUÇÃO}

A aceleração da urbanização e o crescimento numérico e territorial das cidades estão entre os mais contundentes impactos do processo de globalização econômica. No Brasil, sob a égide da revolução tecnológica, ocorre um intenso processo de urbanização, transformando seu espaço geográfico, cuja organização, dinâmica e paisagem contrastam com as existentes antes do atual sistema, e que conforme a denominação de Santos (1985, 1988, 1996), classificamos de período técnico-científico-informacional.

A expansão dos modernos sistemas de objetos (Santos, 1994, 1996), especialmente associados aos transportes, às comunicações, à eletrificação e ao saneamento, equipou o território nacional para a modernização agrícola e industrial, assim como para a intensificação das trocas comerciais, possibilitando a integração territorial do país, interligando áreas até então desconectadas. O resultado foi uma significativa dispersão espacial da produção e do consumo, com um conseqüente processo de especialização da produção, estreitando as relações entre as diferentes regiôes do país, multiplicando a quantidade de fixos e fluxos, de matéria e de informação por todo o território nacional, e disseminando diferentes arranjos produtivos.

Tudo isso fez da urbanização brasileira contemporânea um fenômeno complexo e diferenciado, dada a multiplicidade de variáveis que nela passam a interferir. Quanto maior
1 Trabalho apresentado no XII Encontro da Associação Nacional de Pós-Graduação e Pesquisa em Planejamento Urbano e Regional, de 21 a 25 de maio de 2007, na cidade de Belém (Pará). 0 presente artigo é fruto de estudos desenvolvidos pelos autores no projeto integrado de pesquisa intitulado "Economia Política da Urbanização do Baixo Jaguaribe (CE)", que contou com o apoio do CNPq. 
e mais extensa se torna a divisão do trabalho, mais intenso e complexo é o processo de urbanização. Paralelamente, ocorre um grande crescimento populacional, culminando em uma nova divisão territorial e social do trabalho, uma nova repartição dos instrumentos de trabalho, do emprego e dos homens e mulheres no território do país.

No período de cinqüenta anos ocorre uma verdadeira inversão da distribuição da população no Brasil, com uma generalização da urbanização da sociedade e do território. Com a globalização, reestruturaram-se a produção e o território preexistentes, desorganizando as estruturas, as funções e as formas antigas. Cada vez que o território é reelaborado para atender à produção globalizada, superpõem-se novos fixos artificiais, aumentando a complexidade dos seus sistemas técnicos e de suas rugosidades.

O dinamismo da produção do território brasileiro das últimas décadas pode ser revelado pela reestruturação produtiva da agropecuária e da indústria; pela expansão do comércio e dos serviços; pelas novas localizaçôes da indústria, em parte propiciadas pela luta dos lugares pelos investimentos produtivos; pela expansão das indústrias de base tecnológica; pelo aumento da quantidade e qualidade do trabalho intelectual; pela expansão de novas formas de consumo; pelos intensos movimentos migratórios, entre outros.

Uma das vias de reconhecimento da sociedade e do território brasileiros atuais é o estudo da reestruturação produtiva da agropecuária, que se processa nas últimas décadas. Desde então, organiza-se e difunde-se um novo modelo econômico de produção agropecuária, que aqui denominamos de agronegócio. Muitos novos espaços agrícolas são disponibilizados à produção agrícola moderna nas últimas décadas.

Nesse contexto, também o semi-árido e os cerrados nordestinos, que, de certa forma, compunham o exército de lugares de reserva, tornaram-se atrativos e foram ou estão sendo incorporados ao agronegócio, especialmente os vales úmidos (São Francisco, Açu, Jaguaribe), associados à fruticultura, e os cerrados (sul do Maranhão, do Piauí e oeste da Bahia), associados à expansão da produção de soja, ampliando formas intensivas de produção.

Dentre as características do agronegócio globalizado está sua forte integração à economia urbana, gerando uma extensa gama de novas relações campo-cidade, diluindo, em parte, a clássica dicotomia entre estes dois subespaços. As cidades próximas às áreas de realização do agronegócio tornam-se responsáveis pelo suprimento de suas principais demandas, seja de mão-de-obra, de recursos financeiros, aportes jurídicos, de insumos, de máquinas, de assistência técnica etc, aumentando a economia urbana e promovendo redefiniçōes regionais - denotando o que Milton Santos (1988, 1993, 1994, 1996, 2000) chamou de cidade do campo. Considerando nossos estudos atuais, acreditamos que podemos adaptar a noção de cidade do campo para cidade do agronegócio para classificar algumas das cidades, locais e médias, do Brasil agrícola com áreas urbanas.

Esta noção deve ser vista como a materialização das condições gerais de reprodução do capital do agronegócio globalizado, cujas funções principais associam-se às crescentes demandas de novos produtos e serviços especializados, o que promove o crescimento do tamanho e do número das cidades no Brasil agrícola moderno, onde se processa a reestruturação produtiva da agropecuária.

Assim sendo, quanto mais se intensifica o capitalismo no campo, mais urbana se torna a regulação da agropecuária, sua gestão, sua normatização. Quanto mais dinâmica a reestruturação produtiva da agropecuária, quanto mais globalizados os seus circuitos espaciais da produção e seus círculos de cooperação (Santos, 1986a, 1988; Elias, 2003), maiores e mais complexas se tornam as relaçóes campo-cidade, resultando em uma significativa remodelação do território e na organização de um novo sistema urbano, com a multiplica- 
ção de pequenas e médias cidades, que compõem lugares importantes para a realização do agronegócio globalizado. Da mesma forma, considerando que a difusão do agronegócio globalizado se dá de forma social e espacialmente excludentes, sua difusão promove o acirramento das desigualdades socioespaciais também nas cidades do agronegócio.

O presente artigo tem, assim, o objetivo de discutir esta tipologia de cidade, que aqui denominamos de cidade do agronegócio, assim como as desigualdades socioespaciais que nela se reproduzem. Como objetos de análise, foram escolhidas algumas cidades que poderiam ser classificadas como do agronegócio do Nordeste, especialmente Limoeiro do Norte (CE), Petrolina (PE), Balsas (MA) e Barreiras (BA), sendo que as duas primeiras associam-se ao agronegócio da fruticultura e as duas últimas ao agronegócio dos grãos, em especial da soja.

Vale destacar que cada uma destas cidades polariza uma respectiva região, assumindo posição de destaque em redes de cidades já consolidadas, reunindo tanto aquelas associadas ao agronegócio quanto outras que ainda permanecem em padróes tradicionais de produção, o que configura intensas disparidades intra-regionais. A moradia é a variável principal escolhida para análise, o que leva a constituir um conjunto de processos adjacentes e a evidenciar as especificidades que as distinguem de outras realidades urbanas.

São, a seguir, apresentados alguns elementos metodológicos utilizados, de forma a contribuir com a identificação das interfaces axiais presentes nas cidades supracitadas e a formulação de uma síntese que possa nortear as similaridades entre as realidades percebidas nos diferentes municípios analisados. São discutidos, também, os principais processos até aqui constatados, com o objetivo de sistematizar o conjunto de pressóes que levam à ocorrência dos mesmos, assim como os impactos derivados e as possíveis respostas até aqui propostas pelos diferentes atores. São trabalhados, ainda, alguns elementos relacionados à questão do déficit habitacional e da condição inadequada de moradia nestes municípios.

\section{URBANIZAÇÃO DISPERSA E EMERGÊNCIA DA CIDADE DO AGRONEGÓCIO}

No Brasil, o intenso processo de urbanização das últimas décadas contrasta com o país do período pré-técnico-científico-informacional, essencialmente agrário. $\mathrm{O}$ fenômeno da metropolização se implanta a partir dos anos 1950 e, há muito, suplanta a classificação inicial que admitia a classificação de nove Regiôes Metropolitanas.

Em um primeiro momento da aceleração urbana brasileira ocorre uma crescente concentração das atividades econômicas e da população em algumas poucas cidades, que crescem de maneira caótica. As novas formas de produção e consumo, associadas aos novos padrões econômicos e culturais, não poderiam se instalar em outro meio que não o dessas grandes cidades, as quais se tornam metrópoles como resultado da aceleração do processo de modernização e urbanização que lhes atribui um papel de macro-organização da economia e do território.

Entre 1950 e 1980, ocorreu uma crescente concentração das atividades econômicas e da sua população em umas poucas cidades. Uma parte bastante substancial do incremento demográfico do país ocorreu justamente nas áreas metropolitanas, para as quais se dirigiram grandes levas de migrantes, especialmente nas décadas de 1960 e 1970, uma vez que, em razão das economias de aglomeração, as metrópoles tiveram reforçado o seu papel de principais focos da atividade econômica do país. 
Considerando a tendência predominante no capitalismo de algumas áreas acumularem a maior parte dos recursos técnicos e econômicos, a base atual da organização da produção brasileira, resultado da herança histórica e da velocidade de difusão das inovações, revela-nos que a reestruturação produtiva se processou de forma mais intensa nas Regiōes Sudeste e Sul. Nestas, a difusão de inovações foi mais veloz e complexa, com uma contínua renovação das forças produtivas e do território, que responderam com grande rapidez às necessidades colocadas pelos agentes econômicos.

Esta seria, de acordo com Santos (1986b, 1993), a Região Concentrada do Brasil, na qual, desde o primeiro momento da mecanização do território, ocorre uma adaptação progressiva e eficiente aos interesses do capital hegemônico, reconstituindo-se à imagem do presente, transformando-se na área com maior expressão dos fixos artificiais e dos fluxos de todas as naturezas. Esta seria a área do país onde o meio técnico-científico-informacional (Santos, 1988, 1996) se dá de forma contígua. Mas, mesmo na Região Concentrada há acumulação dos recursos em certas áreas, e o Estado de São Paulo se destaca como o seu núcleo principal, onde as inovações mais se difundiram.

Porém, desde a década de 1980, segundo Milton Santos (1993) em seu livro A Urbanização Brasileira, processa-se uma verdadeira revolução urbana no Brasil. Desde então, a urbanização deixa de ser apenas litorânea e se interioriza, com uma forte tendência à ocupação periférica do território, levando à generalização do processo de urbanização tanto da sociedade quanto do território, desencadeando um incomensurável número de transformações nas áreas mais longínquas do país. Concomitantemente aos processos de urbanização e metropolização, com a construção de grandes cidades desenvolveram-se também cidades médias e pequenas, tornando muito mais complexa a rede urbana brasileira, uma vez que aumentaram tanto os fatores de concentração quanto os de dispersão. A divisão do trabalho resultante, mais intensa e extensa, acabou por consagrar a tendência à ocupação periférica do território nacional.

Diante disso, durante o processo de aceleração da difusão de inovações, as migrações passam a ocupar não apenas as regiōes metropolitanas, mas também as cidades menores, especialmente nas áreas que de maneira mais rápida reorganizaram a produção e o território.

A adição de produtos químicos, a utilização da biotecnologia, o uso intensivo de máquinas agrícolas, entre outros, mudando a composição técnica e orgânica da terra (Santos, 1994), fizeram se difundir também no espaço agrário o meio técnico-científico-informacional, o que explica, em parte, a interiorização da urbanização. Processa-se, assim, um crescimento de áreas urbanizadas também no campo, notadamente nas áreas que se modernizam, uma vez que, entre outras coisas, a gestão do agronegócio globalizado necessita da sociabilidade e dos espaços urbanos.

Embora as grandes cidades se constituam no âmago da dinâmica econômica globalizada, outros agentes passam a se apresentar com força para receber e emitir fluxos de várias naturezas e intensidades, o que resulta na criação de uma gama de novas relações sobre o território. Hoje se conhece uma série de atividades, incluindo as agropecuárias e as agroindustriais, que criam relaçóes que escapam ao seu entorno imediato e buscam nexos distantes, desenhando uma verdadeira teia de circuitos espaciais de produção e círculos de cooperação globalizados (Santos, 1986a; Elias, 2003), sendo que vários destes circuitos e círculos encontram-se no Brasil agrícola.

O Brasil chega, assim, ao século XXI com uma generalização do fenômeno da urbanização da sociedade e do território. A conseqüência é a geração de um território altamente diferenciado, e muito mais complexo na sua definição, do que o foi no período pré- 
técnico-científico-informacional, o que torna praticamente inviável a continuidade da separação tradicional entre um Brasil urbano e um Brasil rural, assim como a falência dos esquemas clássicos de análise da rede urbana, da definição das regiōes metropolitanas e da divisão regional do país. Com isso, revela-se a necessidade de uma revisão de uma série de critérios - em parte até hoje muito utilizados - que considere a complexidade da realidade atual.

Diante disso, concordamos com Santos (1993) que é impossível continuar simplesmente dividindo o Brasil entre urbano e rural. Para o autor, uma divisão entre o Brasil urbano com áreas agrícolas e um Brasil agrícola com áreas urbanas refletiria melhor a realidade contemporânea do país.

É possível identificar várias áreas nas quais a urbanização se deve diretamente à consecução do agronegócio globalizado. A reestruturação destas atividades acelera o processo de urbanização e de produção de espaços urbanos não metropolitanos, cujos vínculos importantes se devem às inter-relações cada vez maiores entre o campo e a cidade. Estas se desenvolvem atreladas às atividades agrícolas circundantes e dependem delas, em graus diversos, e cuja produção e consumo se dão de forma globalizada.

Dessa forma, a reestruturação produtiva da agropecuária brasileira está entre os processos que promovem o aprofundamento da divisão social e territorial do trabalho, contribuindo para uma total remodelação do território e a organização de um novo sistema urbano. As novas relações campo-cidade impostas pelo agronegócio globalizado representam um papel fundamental para a expansão da urbanização e para o crescimento das cidades médias e locais, fortalecendo-as, em termos demográficos ou econômicos. E seus elementos estruturantes podem ser encontrados na expansão das novas relações de trabalho agropecuário, promovendo o êxodo rural (migração ascendente) e a migração descendente (Santos, 1993) de profissionais especializados no agronegócio, assim como na difusão do consumo produtivo agrícola (Santos, 1988; Elias, 2003), dinamizando o terciário e, conseqüentemente, a economia urbana - o que revela que é na cidade que se realizam a regulação, a gestão e a normatização das transformações do campo moderno.

A consecução do agronegócio globalizado se dá com a formação de redes agroindustriais globalizadas que associam empresas agropecuárias, fornecedores de insumos químicos e implementos mecânicos, laboratórios de pesquisa biotecnológica, prestadores de serviços, agroindústrias, empresas de distribuição comercial, empresas de pesquisa agropecuária, empresas de marketing, cadeias de supermercados, empresas de fast food etc. E que resultam na intensificação da divisão do trabalho, das trocas intersetoriais, da especialização da produção e em diferentes arranjos territoriais produtivos no campo e nas cidades que lhe são próximas, evidenciando o aprofundamento da territorialização do capital no campo e da oligopolização do espaço agrário.

O impacto de todas essas transformações na dinâmica populacional e na estrutura demográfica vem sendo intenso. Concomitantemente a uma reestruturação produtiva agropecuária e agroindustrial, ocorre uma revolução demográfica e urbana, marcada por grande crescimento populacional. Uma das características do processo de modernização das atividades agropecuárias no Brasil é o desenvolvimento de uma gama muito extensa de novas relações campo-cidade, dada a crescente integração da agropecuária ao circuito da economia urbana. Isto se dá, principalmente, porque $o$ agronegócio globalizado tem o poder de impor especializações territoriais cada vez mais profundas.

Dessa forma, quanto mais se difunde o agronegócio globalizado, mais urbana se torna a sua regulação, e se produzem cidades do agronegócio, que passam a desempenhar 
novas funções, transformando-se em lugares de todas as formas de cooperação erigidas pelo agronegócio globalizado e resultando em muitas novas territorialidades. Se a cidade é a materialização das condições gerais de reprodução do capital (Carlos, 2004), a cidade do agronegócio é aquela cujas funções de atendimento às demandas do agronegócio globalizado são hegemônicas sobre as demais funções.

Nas áreas de expansão do agronegócio globalizado é visível o crescimento da urbanização e de aglomerados urbanos, assim como a criação de novos municípios. É possível mesmo observar uma rede de cidades do agronegócio, considerando as diferentes demandas de seus diversos ramos. Isto pode ser observado especialmente na Região Concentrada, tendo destaque as cidades médias, que já estariam em estágio mais avançado de urbanização.

As cidades do agronegócio no Brasil têm-se desenvolvido atreladas às atividades agrícolas e agroindustriais circundantes, e dependem, em graus diversos, dessas atividades, cuja produção e consumo se dão, em grande parte, de forma globalizada. Rio Verde (GO), Sorriso, Primavera do Leste e Rondonópolis (MT), Sertãozinho, Matão e Bebedouro (SP) são exemplos de cidades do agronegócio.

Poderíamos citar alguns exemplos da recente ocupação de lugares de reserva na Região Nordeste, sejam associados à expansão da fruticultura nos vales úmidos, como Petrolina (PE) e, mais recentemente, Limoeiro do Norte (CE), ou à expansão da soja nos cerrados, que se dá em uníssono com a implantação das multinacionais Cargill e Bunge desestruturando a formação socioespacial anterior, trazendo novas dinâmicas territoriais, políticas e socioculturais ao entorno, como ocorre em Balsas (MA), Uruçuí e Bom Jesus (PI), Barreiras e Luís Eduardo Magalhães (BA).

Luis Eduardo Magalhães é um dos últimos municípios criados como resultado das novas formas de uso e gestão do território brasileiro inerentes à expansão do agronegócio globalizado da soja. Criado no ano de 2000, pertencia ao município de Barreiras, principal centro urbano dos cerrados nordestinos, o primeiro a despontar com a economia atrelada ao agronegócio da soja no Nordeste, como já apontavam Santos Filho e Fernandes (1988), ainda na década de 1980.

\section{DESIGUALDADES SOCIOESPACIAIS NAS CIDADES DO AGRONEGÓCIO}

A difusão do agronegócio globalizado no Nordeste brasileiro, seja de frutas tropicais ou de soja, vem promovendo metamorfoses de inúmeras naturezas. Dentre os impactos negativos deste processo, destacaríamos: a crescente desarticulação da agricultura de subsistência e aumento da participação de empresas agropecuárias no total da produção agropecuária regional; a expansão da monocultura e, conseqüentemente, diminuição da biodiversidade e aumento do processo de erosão genética; a mudança dos sistemas técnicos agrícolas, com difusão de um pacote tecnológico dominado por uma produção oligopolizada e muitas vezes impróprio para as condições ambientais regionais, destruindo saberes e fazeres historicamente construídos. E ainda: o aumento da concentração fundiária, com a expropriação de agricultores que não detêm a propriedade da terra; o aquecimento do mercado de terras, que tem seus preços aumentados, contrariando ainda mais as aspirações pela Reforma Agrária; o acirramento da privatização da água, com as novas formas de normatização de seu uso, configurando uma situação de hidronegócio; a formação de 
um mercado de trabalho agrícola formal, com a expansão do trabalho assalariado, seja braçal ou especializado; a fragmentação do espaço agrário, diferenciando cada vez mais os espaços da produção e compondo arranjos territoriais produtivos agrícolas; o incremento da economia urbana e das cidades locais e médias; o crescimento desordenado de algumas cidades, com o conseqüente aumento das periferias urbanas e carências de infra-estrutura.

São visíveis as novas territorialidades na região Nordeste, no campo e nas cidades, pontos de transformação da natureza, de criação de novas horizontalidades e verticalidades e da articulação da escala local com a planetária, expandindo o processo de territorialização do capital no campo. Mas, a reestruturação produtiva da agropecuária acentua as históricas desigualdades socioespaciais, além de criar muitas outras. Dessa forma, se processa uma produção regulada pelo mercado associado aos novos padróes de consumo alimentar de frutas frescas e de derivados de soja, sob o comando de grandes grupos hegemônicos do sistema alimentar, o que resulta na refuncionalização dos espaços agrários e urbanos e na difusão de especializações produtivas que mantêm traços estruturais da região, dissociados do projeto de formação de uma sociedade mais justa e equilibrada.

Tudo isto vem se refletindo nas cidades do agronegócio, que passam a reproduzir os mesmos problemas urbanos das cidades maiores. Destacaríamos: ausência ou insuficiência de infra-estrutura social (creches, escolas, postos de saúde) nas áreas habitadas pela população de menor renda; surgimento de áreas de ocupação em situação de risco ambiental; favelização nos espaços destinados a usos institucionais e áreas verdes; disseminação de vazios urbanos promovendo a especulação imobiliária; loteamentos periféricos clandestinos desprovidos de infra-estrutura; congestionamento nas áreas centrais por movimentação de carga e descarga, dentre outros.

$\mathrm{Na}$ busca da compreensão do processo de urbanização e das transformações intraurbanas vigentes nos pontos luminosos de crescimento econômico associados ao agronegócio globalizado nas fronteiras agrícolas da fruticultura e da soja no Nordeste, foram identificados vários processos que se repetem, apesar da diversidade da realidade econômica, sócio-ambiental e cultural presente no semi-árido e nos cerrados nordestinos. Estes processos se encontram diretamente relacionados ao intenso e rápido crescimento demográfico pelo qual têm passado as sedes dos municípios-pólo, assim como a uma redistribuição espacial da população nas respectivas regiōes, levando a uma aceleração da migração intra-regional. Além disso, vale mencionar o maior fluxo migratório proveniente das regiōes vizinhas e de outros Estados, o que deflagra um crescimento urbano desordenado, visível na forma como as cidades se expandem ao longo de seu sistema viário regional, ou mesmo nas vias intra-municipais de acesso às sedes distritais e localidades rurais. Com isso, surge uma série de problemas atrelados à circulação e à mobilidade urbana e regional, atingindo tanto as áreas centrais das cidades como as periféricas, os espaços de transição e as localidades rurais mais longínquas.

Fato é que a possibilidade desigual de acesso aos equipamentos sociais e às redes de infra-estrutura entre as populações das áreas urbana e rural, assim como a centralização das instituições públicas e dos serviços nos municípios-pólos já vêm contribuindo para a aceleração desse fenômeno de urbanização, tornando-se ainda mais evidentes nas áreas onde a reestruturação produtiva da agropecuária concentra a propriedade da terra e diferencia as partes que compõem a região - seja nas relaçôes de trabalho, seja na alocação de investimentos.

Deste crescimento urbano predominantemente excludente emergem diversas questôes associadas à forma desigual como se dá o acesso aos benefícios trazidos pela urbanização, assim como aos conflitos e incompatibilidades de uso e ocupação do território, le- 
vando ao surgimento de marcas de degradação ambiental comprometedoras das condições de habitabilidade em diferentes escalas. A implantação de agroindústrias dissociada de estudos de adequação do uso do solo; a presença de estabelecimentos comerciais atacadistas que remanescem nos centros; usos institucionais considerados impactantes sobre o meio urbano (como matadouros, aterros sanitários, cemitérios) são alguns dos processos que têm colaborado de forma negativa para a deterioração da paisagem em determinadas cidades do agronegócio.

Todavia, é na construção dos espaços residenciais, sejam eles formais ou informais, legais ou ilegais, promovidos pelo poder público ou pelo setor privado, tecnicamente assistidos ou auto-construídos, que se perceberá a forma mais predatória com que a expansão da urbanização tem se dado, tanto nas áreas centrais como nas áreas intermediárias, peri-urbanas ou mesmo em zonas de transição urbano-rural.

Compreendendo o espaço como síntese da interação entre os processos naturais e as relações sociais de produção e adotando-se as formas como a moradia se configura na paisagem como referência, os diferentes fenômenos foram agrupados segundo as seguintes questôes: favelização; mercado imobiliário; produção de habitação de interesse social pelo Estado; déficit habitacional e condiçôes inadequadas de moradia.

No que concerne à favelização, considerando a favela como intervenção informal e forma mais precária de moradia, em que a população não detém a propriedade da terra, teríamos a situação de irregularidade fundiária em desacordo com as normas urbanísticas; a intensificação da favelização nos espaços de propriedade do poder público e nas áreas de proteção ambiental; o aumento das áreas em situação de risco; a precariedade das condições de moradia refletindo na qualidade de vida da população; o surgimento de formas precárias de moradia com características urbanas agrupadas em áreas rurais próximas às áreas produtivas, acompanhado de crescimento populacional.

Outrora concentradas nas áreas metropolitanas, as áreas de ocupação passam a se incorporar à paisagem urbana em número cada vez maior de cidades, independente do seu contingente populacional. Considerando a expansão da agricultura nas regiões polarizadas pelas cidades do agronegócio, os impactos da concentração da posse da terra e da mecanização da agricultura em áreas onde predominava a agricultura familiar podem ser percebidos com o surgimento de novas formas de moradia na cidade.

Utilizando a nomenclatura de Carvalho (2003), a presença de favelas, por ele denominadas como "pontas de rua", pode ser minimamente quantificada a partir do número de entradas da cidade, tanto de caráter regional como local, visto que em cada uma delas normalmente se encontra uma área de ocupação que abriga famílias provenientes do campo, e que reúne habitaçóes improvisadas, feitas em materiais rústicos, muitas vezes de apenas um cômodo, quase sempre sem banheiro.

Independentemente de padrões urbanísticos normativos e mesmo daqueles tradicionais historicamente construídos, as cidades passam a ter sua periferia constituída por micro-espaços desordenados, o que dificulta a implantação das redes de infra-estrutura, bem como a sua acessibilidade, além de impedir as boas condições de mobilidade da população moradora (Pasternak, 1997).

Dentre os efeitos da favelização, pode ser mencionado o comprometimento das condiçóes ambientais dos espaços livres periféricos e das margens de rios e lagoas, alvos preferenciais das novas ocupações, nos quais se reproduzem as velhas formas de implantação de assentamentos, dando as costas para os recursos hídricos. Em casos extremos, já se comprova a presença de áreas de risco, dado que parte das cidades do agronegócio nor- 
destinas consideradas para análise apresenta condiçōes de semi-aridez, com inundações recorrentes nas áreas alagáveis irregularmente ocupadas, assim como solapamento das margens de rios em situação de enchente, merecendo maiores cuidados no controle de futuras ocupações e na formulação de políticas de remoção e reassentamento em áreas ambientalmente estáveis.

A condição socioeconômica de extrema carência associada à situação fundiária precária da grande maioria das famílias também contribui para o estabelecimento de vínculos de dependência com os novos senhores da terra, predominando a cessão de uso informal para fins de moradia.

Nas cidades do agronegócio mais recentemente constituídas, na sua mudança de função, o processo de favelização mostra-se ainda mais acentuado, e suas atuais condições para construção de moradias colaboram para que estes espaços retratem ainda mais a situação de pobreza, desigualdade e exclusão, como impactos característicos das novas relações de produção trazidas pela intensificação do capitalismo no campo.

Verdadeiros guetos de miseráveis, as favelas já estão também no campo, alocadas nas pequenas localidades que margeiam as áreas de produção agrícola, como no município de Limoeiro do Norte (CE). Centenas de moradias precárias podem ser vistas em pelo menos quatro aglomerados próximos das áreas da produção intensiva de frutas na Chapada do Apodi. Localidades denominadas Km 60, Sucupira, Cabeça Preta, Km 69, dentre outras, reúnem famílias que têm na oportunidade de oferta do trabalho informal sazonal sua grande motivação. Processo similar foi constatado no interior dos projetos públicos de irrigação em Petrolina (PE), onde passaram a se formar alguns núcleos habitacionais de novas famílias constituídas no próprio perímetro, e mesmo de antigos irrigantes que se desfizeram de seus lotes, e que nele permaneceram como trabalhadores agrícolas assalariados.

A situação de precariedade, recentemente identificada, remonta aos padrões e aspectos da favelização nas grandes cidades durante a década de 1970 e 80 , quando as famílias não investiam na melhoria da habitação, até mesmo por conta da instabilidade da não propriedade da terra, do predomínio de moradias feitas em taipa, desprovidas de infra-estrutura. Todavia, a chegada de um número cada vez maior de migrantes provenientes de municípios e estados vizinhos tende a consolidar a ocupação, antevendo-se futuros conflitos fundiários.

No caso do mercado imobiliário, no que se refere à produção da moradia com a atuação do setor imobiliário local, ainda que incipiente, são apontados dentre outros fenômenos: a dinamização do mercado imobiliário a partir da implantação de loteamentos para famílias de renda média e disponibilidade de imóveis para aluguel; a verticalização nas áreas centrais atendendo às demandas específicas, associadas à super utilização do lote urbano e à segregação socioespacial; a presença de vazios urbanos promovendo a especulação imobiliária; a implantação de loteamentos irregulares e clandestinos sem infra-estrutura e sem nenhum critério urbanístico.

É notória a formação de um mercado imobiliário no âmbito do espaço intra-urbano da cidade do agronegócio como reflexo da intensificação das demandas do mercado globalizado. Outrora pautada em procedimentos informais de locação para fins residenciais, a presença de imobiliárias já denota a diversificação do perfil de moradores, representando a chegada de profissionais demandados pelas novas funçôes assumidas pelas cidades, como a de fornecer os insumos modernos, a mão-de-obra especializada, os implementos agrícolas, dentre outras. 
Em Limoeiro do Norte (CE), desde o início de 2005, passa a funcionar a primeira imobiliária na cidade cuja especialidade é a realização de contratos de locação. Vale lembrar que a mesma imobiliária já funcionava em outro município da região, e no entanto, tinha como principal produto a venda de lotes em parcelamentos periféricos para atender a demanda local. Situação semelhante foi observada em outros municípios, como em Balsas (MA), Barreiras (BA) e mesmo em outros de menor porte, como Uruçuí (PI), sempre atendendo à demanda de novos trabalhadores especializados, que passam a aquecer o mercado imobiliário.

O mesmo pode ser dito a partir do crescimento da construção civil, percebido através do surgimento de uma verticalização, ainda de forma incipiente, abrigando moradores temporários - como os representantes comerciais, os prestadores de serviços e mesmo os estudantes de cursos de nível superior, que também passam a simbolizar a modernização e a polarização destas cidades em relação às regióes circunvizinhas. Disto resulta um conjunto de edificações sob a forma de flats, semelhantes a antigos kitnets, especialmente localizados nas áreas centrais, em pisos superiores aos estabelecimentos comerciais, geralmente de propriedade do mesmo empreendedor.

Situações extremas já foram percebidas, como o surgimento de edifícios verticais de alto padrão, apesar da disponibilidade de terra urbana, especialmente nas cidades mais consolidadas, como Barreiras (BA) e Petrolina (PE), e mesmo em Luís Eduardo Magalhães (BA). O mesmo pode ser dito da implantação de pequenos condomínios fechados e loteamentos afastados da cidade, levando para estas cidades padrōes residenciais metropolitanos, o que exacerba a dicotomia entre as áreas de segregação voluntária daqueles com maior poder aquisitivo e as áreas de exclusão social de outros desprovidos dos benefícios trazidos com a urbanização e seus rebatimentos na cidade do agronegócio. Desta maneira, percebe-se a reprodução de estratégias de apropriação dos investimentos públicos pelas classes dominantes, com a segregação em áreas de maior valor imobiliário devido às infra-estruturas e aos serviços disponíveis (Villaça, 1999).

O processo de verticalização ao longo das margens do rio São Francisco, em Petrolina (PE), no trecho já urbanizado próximo ao centro, pode ser mencionado como claro exemplo de apropriação dos investimentos em infra-estrutura, o que eleva o preço da terra e consolida o processo de substituição de antigas residências por edifícios multi-familiares. Mesmo nas partes mais distantes do centro, porém, ainda margeando o rio São Francisco, observa-se a implantação de condomínios fechados, os quais se apropriam das boas condições de mobilidade e das vantagens paisagísticas. Em Barreiras (BA), a segregação socioespacial também se dá nos bairros próximos ao centro, áreas melhor providas de infra-estrutura, que fazem emergir uma verticalização pontual, denotando, porém, a alta concentração de riqueza gerada pelo agronegócio.

Como impacto deste processo, há a ocorrência de vazios urbanos mantidos em áreas dotadas de infra-estrutura para empreendimentos imobiliários futuros; o poder de compra das classes melhor favorecidas contribui, por sua vez, para o encarecimento da implantação de redes de infra-estrutura para as periferias, cada vez mais distantes.

Vale ressaltar que em municípios cujas atividades produtivas permitem um maior emprego da população local, como nas cidades que possuem agroindústrias, o mercado imobiliário formal também já se faz presente, promovendo, muitas vezes, loteamentos irregulares, desconectados de diretrizes urbanísticas. Com isso, a população inserida no mercado formal de trabalho procura adquirir lotes urbanos para possíveis investimentos. 
No caso do município de Balsas (MA), onde a taxa de urbanização já ultrapassa $84 \%$, observa-se a proliferação de loteamentos, os quais, ainda que justapostos, contribuem com o crescimento desordenado da cidade. Com isso, ocorre uma setorização das famílias de melhor poder aquisitivo ao sudeste da área central, onde se verifica a presença de condomínios fechados, que constroem parte da sua própria infra-estrutura. Mesmo na pequena Uruçui (PI) já se observa um loteamento a $15 \mathrm{~km}$ da sede municipal, nas proximidades da unidade esmagadora de soja instalada no município, pertencente à multinacional Bunge, o que indica uma nova frente de urbanização isolada e diferenciada da precária situação existente na cidade. Em Barreiras (BA), e especialmente em Luís Eduardo Magalhães (BA), é possível notar a clara distinção entre os alvos do mercado imobiliário, a partir do eixo de ligação entre as duas cidades como lócus preferido para loteamentos de melhor padrão, ao contrário das vias de saídas para o Piauí (Barreiras) e Brasília (Luis Eduardo Magalhães), locais em que as famílias de menor poder aquisitivo têm se assentado, ainda que desprovidas de infra-estrutura.

Para que esse novo perfil de demanda possa ser incorporado, segundo a lógica de acumulação que domina o mercado imobiliário formal, faz-se necessária sua precarização, transferindo-se para o poder público e para a municipalidade como um todo os custos da urbanização. Com isso, produzem-se loteamentos irregulares conforme o que determina a lei, e desconsidera-se também a doação de áreas para equipamentos sociais, espaços livres e preservação ambiental. (Campos, 1992)

No que concerne à produção de habitação de interesse social, diríamos que na intervenção do poder público, nas diferentes esferas de governo em ações voltadas para a produção da moradia, é possível identificar alguns processos, dentre os quais: construção de conjuntos habitacionais em áreas periféricas desprovidas de infra-estrutura e sem qualquer interligação à malha urbana existente, induzindo à expansão urbana; acessibilidade desigual às redes de serviço e infra-estrutura urbanas e aos equipamentos sociais, associada à pobreza urbana; fragmentação das ações habitacionais promovidas pelo poder público, tanto no que se refere à sua materialização como objeto do espaço urbano quanto no aspecto político, relacionado aos planos e programas implementados; fragilidade dos instrumentos de planejamento e gestão do solo urbano, incapazes de amenizar os problemas decorrentes da urbanização, tanto no que se refere à habitação quanto aos problemas relacionados à organização do território.

Observando a realidade da produção da moradia de interesse social, verifica-se que as intervenções realizadas decorrem de programas conduzidos pelo Governo Federal, seja através do extinto Banco Nacional de Habitação (BNH), seja da Caixa Econômica Federal, executados pelos Governos Estaduais através de suas Companhias de Habitação COHABs ou órgãos equivalentes. Nestas ações, pode ser apontada como regra a localização periférica dos conjuntos habitacionais produzidos, o que contribui para um crescimento urbano ainda mais desordenado, permitindo remanescentes espaços vazios nos interstícios das franjas peri-urbanas e áreas centrais. (Maricatto, 2001)

Ainda há grandes vazios urbanos entre a periferia de Limoeiro do Norte (CE) e a área central, com as franjas peri-urbanas formadas a partir de projetos habitacionais de interesse social promovidos pelo poder público nas últimas três décadas. Em Barreiras (BA), observa-se um recente projeto habitacional implantado pela prefeitura na saída para o Piauí, que promove o assentamento de famílias provenientes das favelas situadas nas demais entradas da cidade. Todavia, remanescem grandes áreas vazias próximas ao centro, inclusive dotadas de infra-estrutura urbana, o que contribui muito para a espe- 
culação imobiliária. Situação peculiar pode ser constatada em Petrolina (PE), em que os conjuntos habitacionais periféricos induziram à ocupação das áreas vizinhas, e já não há mais condiçôes de expansão em alguns trechos onde os limites do perímetro urbano foram definitivamente atingidos, o que contrapóe assentamentos urbanos e áreas de produção agrícola.

Via de regra, estes conjuntos contam com redes de infra-estrutura, que revelam a situação de acessibilidade desigual aos serviços urbanos como característica também das cidades do agronegócio. Além disso, outros assentamentos periféricos justapostos, os quais já não dispõem dos mesmos benefícios, passam a utilizar a infra-estrutura de forma clandestina, o que leva à sua supersaturação e degradação.

Com a ausência de instrumentos de planejamento e gestão do solo urbano e, principalmente, com a carência de políticas habitacionais de interesse social delineadas segundo as necessidades e possibilidades locais, constrói-se um cenário pouco otimista no ambiente urbano destas cidades. Para reverter esse quadro, é necessária a adoção de medidas que promovam o desenvolvimento institucional, visto que a realidade da questão habitacional já demanda políticas, programas, projetos e, especialmente, técnicos nas instituiçôes locais que sejam capazes de implementá-los.

Quanto ao déficit habitacional e às condiçôes inadequadas de moradia, a expressão quantitativa desses processos pode ser aferida através de estudos recentes feitos pela Fundação João Pinheiro no que se refere ao dimensionamento do déficit habitacional e às condiçóes inadequadas de moradia. Deste estudo, podem ser apontadas como principais características do déficit habitacional associadas às cidades do agronegócio, que também se verificam na análise de áreas metropolitanas, onde o crescimento econômico se mostra igualmente concentrado e desigual. A representatividade do déficit habitacional em relação ao total de domicílios; altos percentuais de domicílios vagos, apesar da demanda; predominância da situação de co-habitação como principal causa do déficit habitacional; complementação quase integral do déficit quando somados; co-habitação e domicílios feitos com materiais rústicos; grande maioria do déficit na faixa de renda inferior a três salários mínimos.

Nas cidades do agronegócio tomadas aqui como referência, observa-se que as taxas de urbanização se mostram em progressivo crescimento, atingindo valores similares às de regiōes metropolitanas: Barreiras (89,4\%), Balsas (84,7\%) e Petrolina (77,8\%). Outros municípios, como Limoeiro do Norte $(58,8 \%)$, ainda que com processos recentes de difusão do agronegócio globalizado, já têm mais da metade de sua população vivendo na zona urbana.

Vale também considerar que a diferença entre o déficit habitacional e o número de domicílios vagos mostra-se bastante reduzida, especialmente nos municípios de porte médio com funções de centros regionais. Nestes casos, tem-se, em um extremo, aqueles com maior aporte de capital investindo na construção de casas para locação, enquanto no outro, percebe-se a expansão da pobreza diretamente associada à relação campo-cidade famílias que no espaço urbano ocupam moradias construídas com materiais rústicos, ou trabalham em domicílios onde residem.

No caso de Barreiras (BA) tem-se um déficit de 6.500 unidades (20,5\% do total de 3.000 domicílios), enquanto mais de 5.400 residências ( $17 \%$ do total de domicílios) encontram-se desocupadas. A situação é similar para o caso de Limoeiro do Norte (CE), onde menos de 1.000 novas casas resolveriam um déficit habitacional de quase 3.000 residências, dado que mais de 2.000 domicílios encontram-se vagos. Vale ressaltar que esse 
contingente de domićlios vazios tem na incapacidade da população local de pagar pelo aluguel um dos principais motivos para a sua desocupação.

A co-habitação como indicador do déficit habitacional em Petrolina (PE) chega a atingir mais de $90 \%$ do total, ao contrário de Limoeiro do Norte (CE) e Balsas (MA), onde o percentual de domicílios rústicos chega a atingir em torno de $30 \%$. Acredita-se que no caso de Petrolina, uma cidade média fortemente associada ao agronegócio, por conta da própria diversidade de funções, além dos investimentos governamentais nos projetos de irrigação, verifica-se uma melhoria gradativa das condiçōes de moradia, com a substituição de materiais precários por outros que garantem melhor condição de vida.

Ainda que não se possa afirmar de forma categórica, a hipótese de que a fruticultura, ao demandar um número maior de empregos (2 a 5 empregos/hectare) em comparação à cultura da soja (1 emprego/100 hectares), promova melhores condições de moradia em cidades como Petrolina do que em cidades que polarizam regiōes de produção da soja, como Balsas, onde notam-se altíssimos índices de miséria. No caso de Limoeiro do Norte, onde o processo de difusão do agronegócio é mais recente, especialmente a partir do início da década de 1990, verifica-se a tendência de redução do índice de domicílios feitos de materiais rústicos - tamanha é a transformação nas suas periferias -, assim como a progressiva diminuição do número de famílias que vive na zona rural e de moradias feitas em taipa.

No que se refere à condição inadequada de moradia, percebe-se uma clara relação entre a localização da pobreza e a precariedade das condições de habitação. As condições sanitárias inadequadas nas cidades do agronegócio do Nordeste demonstram que o desenvolvimento concentrado da forma como se realiza reproduz cada vez mais a lógica da desigualdade, homogeneizando paisagens periféricas, associando a moradia da pobreza à falta de recursos para a construção de instalações sanitárias e à inoperância e capacidade dos municípios implantarem redes de infra-estrutura. Nisto, a situação de Balsas é exemplar: com taxa de urbanização superior a $84 \%, 50 \%$ dos domicílios não possuem banheiro.

\section{CONSIDERAÇÕES FINAIS}

É importante frisar que a reestruturação da agropecuária não homogeneizou a produção ou os espaços agrícolas nem os espaços urbanos que crescem com este processo. O que ocorre em contraposição ao processo de globalização da produção e do consumo agropecuário é um intenso processo de fragmentação da produção e do espaço agrícolas. Assim sendo, como recurso de método para compreensão da urbanização brasileira, do espaço agrário e das cidades do agronegócio, temos que considerar esta fragmentação, que torna cada vez mais diferenciados os espaços.

Diante dos processos identificados nas cidades do agronegócio, cabe afirmar a necessidade de adoção de medidas voltadas para o enfrentamento da questão de moradia. Outrora associada à realidade urbana de grandes cidades, a favelização tanto já se faz presente, como também já se torna mensurável, estando diretamente associada aos fluxos migratórios dirigidos às cidades do agronegócio. Da mesma forma, estas cidades passam a ser alvo de empreendimentos imobiliários em decorrência da riqueza gerada pela reestruturação das atividades produtivas da agropecuária, tornando a construção civil um investimento potencial. 
Denise Elias é coordenadora do Laboratório de Estudos Agrários (LEA/UECE) da Universidade Estadual do Ceará (UECE) e do Grupo de Pesquisa (CNPq) "Globalização e espaços agrícolas", e pesquisadora do CNPq. E-mail: deniselias@uol.com.br

Renato Pequeno é coordenador do Laboratório de Estudos de Arquitetura, Habitação e Ambiente Construído (LEHAU), da Universidade Federal do Ceará (UFC) - Depto. de Arquitetura e Urbanismo. E-mail: luisrenatobp@ uol.com.br

Artigo recebido em maio de 2007 e aprovado para publicação em julho de 2007.
O poder local, por sua vez, dependente de recursos provenientes dos governos federal e estadual, permanece com ações pontuais, desconectadas de uma política habitacional de interesse social. Observa-se que por conta da magnitude do problema, já emergem ações da sociedade civil e de organizações não governamentais no sentido de apresentar projetos demonstrativos como alternativas capazes de gerar impactos positivos nas políticas públicas.

Em estudo mais aprofundado sobre os dados referentes ao déficit e à inadequação habitacional, foi possível constatar o contraste entre o déficit habitacional e a existência de domicílios vagos semelhantes em termos quantitativos. Todavia, ao considerar os dados da inadequação da moradia, percebe-se que, na falta de uma política habitacional de interesse social, seja em escala nacional - na formulação de programas, viabilização e destinação de recursos - seja em escala estadual ou local - na promoção de sua implementação e execução de forma planejada -, os problemas aqui apontados tendem a crescer, comprometendo as condiçôes de habitabilidade urbana.

Os problemas associados à irregularidade fundiária, à concentração de posse da terra urbana e à forma desigual como as redes de infra-estrutura são implementadas, além do descompasso na produção da moradia no que se refere à oferta e à demanda, nos leva a crer que a questão habitacional não será resolvida tão somente através de políticas habitacionais setoriais, mas sim integrando estas últimas às políticas territoriais de desenvolvimento urbano e rural. Assim, considerando que o problema da moradia se apresenta interligado aos conflitos de uso e ocupação do solo, articulado às necessidades de transporte e mobilidade, assim como às demandas por redes de infra-estrutura e equipamentos sociais, cabe retomar o planejamento urbano como estratégia para enfrentar a situação existente.

Tendo em vista os instrumentos legais do Estatuto da Cidade e a valorização dada pelo mesmo ao Plano Diretor como instrumento de política urbana, inclusive ampliando a sua abrangência para todo o município, e não somente para a área urbana, a cidade do agronegócio mostra-se como ambiente propício à formulação de proposições que busquem na cidade soluções para questóes do campo, e neste, as respostas para os problemas urbanos.

\section{REFERÊNCIAS BIBLIOGRÁFICAS}

CAMPOS, C. M. Cidades Brasileiras: seu controle ou o caos. São Paulo: Nobel, 1992.

CARLOS, A. F. A. O Espaço Urbano. São Paulo: Contexto, 2004.

CARVALHO, O. Nordeste: a falta que o planejamento faz. In: GONÇALVES, M. F. (Org.). Regiōes e Cidades, cidades nas regiōes. São Paulo: Unesp, Anpur, 2003.

ELIAS, D. Globalização e Agricultura. São Paulo: Edusp, 2003.

ELIAS, D.; PEQUENO, R. Difusão do agronegócio e novas dinâmicas socioespaciais. Fortaleza: BNB, 2006. 484p.

MARICATO, E. Brasil, Cidades. Petrópolis: Vozes, 2001.

PASTERNAK, S. Favelas e Cortiços no Brasil. São Paulo: LAP, 1997.

SANTOS, M. Espaço e método. São Paulo: Nobel, 1985.

SANTOS, M. Os circuitos espaciais da produção. In: SANTOS, M.; SOUZA, M. A. A. de (Orgs.). A Construção do Espaço. São Paulo: Nobel, 1986a. . A região concentrada e os circuitos produtivos. Relatório de pesquisa $O$ centro 


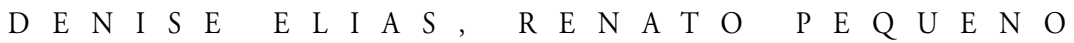

nacional: Crise mundial e redefinição da região polarizada. São Paulo: Depto de Geografia USP, 1986b (datilografado).

- Metamorfoses do espaço habitado. São Paulo: Hucitec, 1988.

. A Urbanização Brasileira. São Paulo: Hucitec, 1993.

. Técnica, espaço, tempo. São Paulo: Hucitec, 1994.

. A natureza do espaço. São Paulo: Hucitec, 1996.

. Por uma outra globalização. Rio de Janeiro: Record, 2000.

SANTOS FILHO, M; FERNANDES, A. A Modernização do campo nos cerrados baianos. Espaço e Debates, ano VIII, 1988, n. 25 (63:75).

VILLAÇA, F. Espaço Intra-urbano no Brasil. São Paulo: Studio Nobel, 1999.

A B S T R A C T In Brazil, deep socio-spatial impacts have been promoted by the territorialization of capital and the oligopoles at the agrarian space, in the countryside and in the cities. This explains partially the process of re-structuring of the territory as well as the organization of a new urban system, which is much more complex, being the result of the spreading of the scientific agriculture and the global agribusiness, which are empowered to impose productive specialization to the territory. In this article, it is defended the thesis of the possibility of identifying in the modern agrarian Brazil, some municipalities which urbanization is directly related to the attainment and the spread of the agribusiness, generating cities, which main function is clearly associated to the productive demands of the sectors partners of the modernization of agriculture, being also important to mention that at these cities the materialization of the general conditions of reproducing the capital of the agribusiness has been realized. Therefore, some presuppositions are presented in order to explain this kind of city, which we denominate by city of the agribusiness. Considering that the spreading of the agribusiness promotes social and spatial exclusion, as well as the incitement of the disparities, we intend to show some aspects of how the cities of agribusiness have been reproduced mainly using the housing as the main variable for this analysis.

K E Y W O R D S Scientific agriculture; agribusiness; urban restructuturing; city of agribusiness; social and spatial disparities. 